\title{
El sistema modular, modelo universitario de articulación interdisciplinaria docencia-investigación-servicio
}

Mario A. Mandujano Valdés ${ }^{1}$

\section{Introducción}

Derivado de la coyuntura social y del contexto histórico-político en México durante 1970, surgió una serie de postulados sobre el papel de la universidad en la sociedad, mismos que permitieron sustentar en 1974 el modelo de la Universidad Autónoma Metropolitana, Unidad-Xochimilco. De esta manera, la universidad propuso nuevas formas de organización que le permitieran construir espacios de vinculación con los problemas de la realidad social nacional (Bojalil, Ortiz, Padilla, Rozo y Santamaría, 1984). En el transcurso de cuatro décadas, el país ha experimentado cambios estructurales en todos los ámbitos institucionales que han profundizado las asimetrías económicas y sociales cuyos efectos han influido en la organización y operación del modelo universitario, generando la necesidad de buscar estrategias de adecuación a las demandas de las nuevas realidades. El reto ha sido no perder el sentido del proyecto académico de la institu-

1 Universidad Autónoma Metropolitana-X. 
ción amenazado por la corriente utilitarista del modelo neoliberal y la visión creciente de universidades homogéneas.

Desde una perspectiva crítica y similar a la propuesta de la UAM-X sobre el papel social de la universidad, se ha considerado como modelo de formación el aprendizaje-servicio, término utilizado para denominar una propuesta pedagógica que vincula en forma articulada las prácticas universitarias con el aprendizaje y el servicio, permitiendo a los estudiantes aplicar los conocimientos al servicio de la comunidad como una forma específica y solidaria de intervención social, al mismo tiempo que les permite adquirir nuevos conocimientos y competencias profesionales en contextos reales de actuación, promoviendo la formación ciudadana activa y el aprendizaje de valores en la práctica (Folgueiras y Martínez, 2009; Francisco y Moliner, 2010; Puig, Gijón, Martín y Rubio, 2011). En este sentido, el aprendizaje-servicio se refiere a una responsabilidad social por parte de la universidad de carácter ético, modelo que además de preocuparse por la calidad académica, orienta su actividad docente y de transferencia del conocimiento al logro del bien común y de una sociedad más justa y democrática (Martínez, 2010).

\section{El Sistema Modular y la interdisciplina}

El Sistema Modular de la UAM-Xochimilco se consideró un proyecto universitario que superó la orientación tradicional, enfatizando la capacidad de profesores y alumnos para construir conocimiento. La estrategia educativa partió del principio de que la realidad implica una serie de relaciones de gran complejidad a la cual no puede accederse en forma inmediata y disciplinaria, sino a través de objetos de transformación, "entendidos como partes de un espacio problematizado socialmente definido" (Bojalil et al., 1984: 18). Los objetos de transformación, al definirse con base en un problema de la realidad y del espacio social de aplicación del conocimiento donde se inserta y opera una práctica profesional, representaron el eje para el diseño de los módulos (unidades de enseñanza-aprendizaje). Cada módulo 
estaría ligado a una práctica profesional e integraría en forma simultánea las tres funciones sustantivas de docencia, investigación y servicio, no en forma fragmentaria de una disciplina en particular, sino de la necesaria contribución de varias disciplinas articuladas en forma interdisciplinaria y no como suma de diversos campos del conocimiento. El proceso formativo en un contexto de trabajo colectivo e interdisciplinario se consideró como la estrategia de posibilidad en la integración del conocimiento para abordar la complejidad que representa el estudio de la realidad social. El sistema modular planteó una modificación de los elementos que conforman la práctica universitaria, es decir, redefinición social de las profesiones y perfiles profesionales para atender los problemas que afectan a los sectores mayoritarios.

\section{El concepto de lo interdisciplinar}

Existen formas simples o de mayor complejidad en la vinculación entre disciplinas. De acuerdo con Piaget (1975: 166), "el nivel inferior podría denominarse multidisciplinariedad" y ocurre cuando la solución de un problema requiere obtener información de una o dos ciencias o sectores del conocimiento, sin que las disciplinas que contribuyen sean cambiadas o enriquecidas (información compartida pero sin interacción verdadera). Designa el término de "interdisciplinariedad a un segundo nivel", donde la cooperación entre varias disciplinas o sectores heterogéneos lleva a interacciones reales o reciprocidad de intercambios que dan como resultado un enriquecimiento mutuo.

Las relaciones recíprocas entre las diversas disciplinas integradas en el abordaje de un objeto de conocimiento en un programa interdisciplinario pueden compararse a los subsistemas de una totalidad y constituirse en varias modalidades (Mandujano, Sánchez y Nájera, 1999), por ejemplo, mediante el enriquecimiento mutuo de los subsistemas que integran la totalidad. Es un caso de asimilaciones recíprocas: las disciplinas se nutren recíprocamente y en la interrelación cada una va tomando de las otras los elementos necesarios para su crecimiento interno 
y para el desarrollo del conjunto. El abordaje interdisciplinario favorece que el conocimiento generado en un campo ayude a esclarecer a otros campos, como posibilidad de reconstruir en su complejidad y totalidad el conocimiento que implica la aproximación a la realidad como sistema, así como el crecimiento equilibrado de los diversos campos como subsistemas.

La coordinación interdisciplinaria entre diversos campos en la construcción de un objeto de estudio dará como resultado la transformación y enriquecimiento del conocimiento e incluso el surgimiento de nuevos campos disciplinarios, lo que no sería posible por la simple yuxtaposición aditiva de disciplinas. En este sentido, por ejemplo, el neurodesarrollo representa un nuevo campo esencialmente interdisciplinario donde se insertan diversos saberes disciplinarios y prácticas profesionales en un mismo objeto de conocimiento; sin embargo, la interdisciplina no se da por sí sola, se requiere una coordinación recíproca entre disciplinas, sus categorías conceptuales y metodologías de abordaje (métodos formalizantes de comprobación y verificación empírica y los no formalizantes o cualitativos, en la explicación y comprensión de la realidad). Para que exista la interdisciplina es necesaria la contribución de conocimientos disciplinarios. Un problema sólo puede explicarse en el contexto de una teoría; existen diversas teorías y metodologías de aproximación a la construcción del objeto de la realidad que pretende ser explicado.

No se trata de confundir con profesionales interdisciplinarios que puedan hacerlo todo, son los campos profesionales los que se enriquecen, permitiendo al profesional al interior de su disciplina particular, vislumbrar en forma más amplia la diversidad de aristas y saberes requeridos en la aproximación de los problemas de la realidad y anticipar nuevas soluciones, desde la especificidad de su propio campo.

El trabajo conjunto de especialistas en diferentes disciplinas no constituye la interdisciplina per se, la posibilidad está en poder articular conocimientos de diversas disciplinas en función de un objeto de transformación. Mainers (1980) considera que lo interdisciplinario es un conocimiento por desarrollar, algo más que la suma de disciplinas, pero en ningún momento un punto de partida. 
La interdisciplina en el modelo universitario de la UAM y en el posgrado de rehabilitación neurológica ha representado una estrategia formativa y metodológica que requiere en el trabajo de docentes y alumnos una toma de conciencia sobre la complejidad que implica conocer la realidad, considerando la multiplicidad de aspectos que la constituyen. Las actividades interdisciplinarias pueden lograr transformaciones que se basen en coordinaciones de nivel superior, sólo en este sentido los profesionales podrán coordinar en nuevos conocimientos o nuevas prácticas los productos de las coordinaciones entre cada disciplina.

\section{Referencias}

Bojalil, L.F., Ortiz, C.E., Padilla, A., Rozo, C. y Santamaría, R. (1984). El Proyecto Académico de la Universidad Autónoma Metropolitana Xochimilco (4ª edición). México: UAM, Unidad Xochimilco.

Folgueiras, P. y Martínez, M. (2009). El desarrollo de competencias en la universidad a través del aprendizaje y servicio solidario. Revista Iberoamericana de Educación para la Democracia, 2(1), 56-76.

Francisco, A.A. y Moliner, M.L. (2010). El aprendizaje servicio en la universidad: una estrategia en la formación de ciudadanía crítica. Revista Electrónica Interuniversitaria de Formación del Profesorado. 13(4), 69-77. Recuperado de http://www. aufop.com/aufop/uploaded_files/articulos/12919992629.pdf.

Mainers, R. (1980). Análisis histórico de la Unidad Xochimilco de la Universidad Autónoma Metropolitana. Documento mimeografiado. México: UAM, Unidad Xochimilco.

Mandujano, V.M., Sánchez, P.C. y Najera, R.M. (1999). La interdisciplina, un proceso vital para el desarrollo de Enfermería. Enfermería de las Américas. Programa de Recursos Humanos ops/OMs. Washington, D.c. Publicación Científica 571.

Martínez, M. (2010). Aprendizaje-Servicio y responsabilidad social de las universidades. Barcelona: Octaedro-ICE-UB. Recuperado de http://www.octaedrotextos.com/pdf/110173.pdf. 
Piaget, J. (1975). Epistemología de las relaciones interdisciplinarias. En: Apostel, L. (Ed.), Interdisciplinariedad. Problemas de la enseñanza y de la investigación en las universidades. México: ANUIES.

Puig, J., Gijón, M., Martín, X. y Rubio, L. (2011). Aprendizaje-Servicio y educación para la ciudadanía. Revista de Educación, número extraordinario, 45-67. 